\title{
Increased Glomerular Thromboxane Synthesis as a Possible Cause of Proteinuria in Experimental Nephrosis
}

\author{
G. Remuzzi, L. Imberti, M. Rossini, C. Morelli, C. Carminati, G. M. Cattaneo, and T. Bertani
}

Mario Negri Institute for Pharmacological Research, Via Gavazzeni 11, Bergamo, and Division of Nephrology and Nuclear Medicine, Ospedali Riuniti, Bergamo, Italy

\begin{abstract}
Altered glomerular metabolism of arachidonic acid (AA) has already been demonstrated in experimental nephrotoxic nephritis. The enhanced synthesis of thromboxane A2 (TxA2) in isolated glomeruli that has been found may mediate changes in renal hemodynamics. The objectives of this investigation were: to check whether glomerular AA metabolism is also altered in a model of glomerulopathy in which no leukocyte infiltration or platelet deposition could be demonstrated; to establish a correlation between the altered AA metabolism and proteinuria; and to explore whether the alteration of the prostaglandin (PG) pathway found in isolated glomeruli is an in vitro artifact or reflects a modification in vivo.

We used a model of glomerular damage characterized by heavy and persistent proteinuria, which was induced in the rat by a single intravenous injection of adriamycin. At light microscopy, minimal glomerular abnormalities were found in this model. Electron microscopy showed profound alterations of glomerular epithelial cells with extensive fusion of foot processes and signs of epithelial cell activation. Electron microscopy of numerous glomeruli showed no platelet deposition or macrophage and leukocyte infiltration in this model.

Isolated glomeruli from nephrotic rats studied 14 or $30 \mathrm{~d}$ after a single intravenous injection of adriamycin $(7.5 \mathrm{mg} / \mathrm{kg})$ when animals were heavily proteinuric generated significantly more TxB2, the stable breakdown product of TxA2, than normal glomeruli. No significant changes were found in the other major AA metabolites formed through cyclooxygenase. Urinary excretion of immunoreactive $\mathrm{TxB2}$ was also significantly higher in nephrotic than in normal animals. Administration of a selective $T x$ synthetase inhibitor, UK-38,485, from day 14 to day 18 after adriamycin resulted in a significant reduction of proteinuria compared with pretreatment values. Glomerular synthesis and urinary excretion of $\mathrm{TxB2}$ were normal during the UK-38,485 treatment. Additional experiments showed that elevated glomerular synthesis and urinary excretion of TxB2 were not a consequence of increased substrate availability. Maximal stimulation of the renin-angiotensin axis with furosemide increased glomerular TxB2 synthesis in normal rats, which was significantly lower than in nephrotic animals. Finally, experiments using a unilateral model of adriamycin nephrosis indicated that the enhancement of glomerular TxB2
\end{abstract}

This work was presented in part at the American Society of Nephrology Annual Meeting in Washington, DC, 1983.

Received for publication 23 January 1984 and in revised form 23 July 1984.

J. Clin. Invest.

(c) The American Society for Clinical Investigation, Inc.

0021-9738/85/01/0094/08 $\$ 1.00$

Volume 75, January 1985, 94-101 synthesis is not simply a consequence of the nephrotic syndrome.

We conclude that: there is an abnormality of glomerular AA metabolism in nephrotic syndrome, which leads to increased TxA2 production; the increased $T \times$ generation correlates with protein excretion and might be responsible for altering the glomerular basement membrane permeability to protein; and the alteration found in isolated glomeruli probably reflects a modification in vivo, in that urinary excretion of immunoreactive TXB2 is also consistently increased in adriamycin nephrosis.

\section{Introduction}

After the initial observation by Smith and Bell (1) that normal glomerular tissue synthesizes prostaglandins (PG), ' several efforts were made to define the role of arachidonate metabolites of glomerular origin in normal conditions and disease. The majority of studies found $\mathrm{PGF}_{2 \alpha}$ and $\mathrm{PGE}_{2}$ to be the predominant glomerular $P G$ in rats, though significant amounts of thromboxane A2 (TxA2) and prostacyclin $\left(\mathrm{PGI}_{2}\right)$ could also be detected (2-5). Glomeruli that were isolated from rats with glycerol-induced acute renal failure synthesized larger amounts of $\mathrm{PGE}_{2}, \mathrm{PGF}_{2 \alpha}$, and TxB2 than appropriate controls (6). It is tempting to speculate that these vasoactive substances have a pathogenetic role in mediating the alterations in regional blood flow typical of acute renal failure.

More recently, Lianos et al. (7) and Dunn (8), using the nephrotoxic nephritis model in rats induced by a single injection of anti-glomerular basement membrane antibody, found that isolated glomeruli from these animals synthesized $\mathrm{Tx}$ at 10 times the rate of control glomeruli. These authors made the important observation that the increased glomerular Tx synthesis correlates linearly with the extent of proteinuria. Whether this reflects a cause and effect relationship, or both glomerular Tx production and proteinuria are two independent markers of glomerular injury, is open to speculation. In order to clarify this issue we studied a model of glomerular damage, which was characterized by heavy and persistent proteinuria, induced in the rat by a single intravenous injection of adriamycin (9).

We report here a significant increase of both glomerular synthesis and urinary excretion of $\mathrm{TxB} 2$ as the obvious alterations of renal arachidonic acid (AA) metabolism in rats affected by adriamycin nephrosis. The increase in TxB2 synthesis is concomitant with the appearance of proteinuria and reaches its maximum at the time of peak proteinuria. Administration of a selective $\mathrm{Tx}$ synthetase inhibitor to nephrotic animals significantly reduces the exaggerated renal TxB2 production and lowers proteinuria in all animals.

1. Abbreviations used in this paper: AA, arachidonic acid; KRB, KrebsRinger phosphate buffer; $\mathrm{PG}$, prostaglandin(s); $\mathrm{PGD}_{2}, \mathrm{PGE}_{2}, 6-\mathrm{Keto}-$ $\mathrm{PGF}_{1 \alpha}, \mathrm{PGF}_{2 \alpha}, \mathrm{PGI}_{2}$, prostaglandins $\mathrm{PGD}_{2}, \mathrm{PGE}_{2}$, 6-Keto-PGF $\mathrm{PG}_{1 \alpha}$, $\mathrm{PGF}_{2 \kappa}$, and $\mathrm{PGI}_{2} ; \mathrm{TLC}$, thin-layer chromatography; Tx, thromboxane; TxA2, TxB2, thromboxanes TxA2 and TxB2. 
We suggest that the mechanism of proteinuria, at least in this experimental model, depends on increased glomerular $\mathbf{T x}$ synthesis, which probably mediates an alteration in the glomerular barrier to proteins.

\section{Methods}

Materials. Adriamycin (Adriblastina) was a gift from Farmitalia Carlo Erba (Milan, Italy). UK-38,485, 3-(1H-imidazol-1-yl-methyl)-2-methyl1H-indole-1-propanoic acid) was kindly provided by Dr. H. M. Tyler, (Pfizer Ltd., Sandwich, United Kingdom). UK-38,485 was dissolved in $0.1 \mathrm{~N}$ sodium hydroxide and the $\mathrm{pH}$ was adjusted to 8.5 with 0.1 $\mathrm{N}$ hydrochloric acid. Furosemide (Lasix) was purchased from Hoechst AG (Frankfurt, Federal Republic of Germany), sulindac (Clinoril) from Merck Sharp \& Dohme (Rome, Italy). Inulin was purchased from E. Merck (Darmstadt, Federal Republic of Germany). AA, bovine serum albumin (BSA), and PG standards for thin-layer chromatography (TLC) studies were obtained from Sigma Chemical Co. (St. Louis, MO). AA was dissolved in $100 \mathrm{mM}$ sodium carbonate, $\mathrm{pH} 10$, and kept under nitrogen. ${ }^{14} \mathrm{C}$-AA $(57.6 \mathrm{mCi} / \mathrm{mmol}),{ }^{3} \mathrm{H}-\mathrm{TxB} 2(150 \mathrm{Ci} /$ $\mathrm{mmol}),{ }^{3} \mathrm{H}-6-\mathrm{Keto} \mathrm{PGF}_{1 \alpha}(130 \mathrm{Ci} / \mathrm{mmol})$, and ${ }^{3} \mathrm{H}-\mathrm{PGE}_{2}(165 \mathrm{Ci} /$ mmol) were purchased from New England Nuclear (Boston, MA). TLC plates (Silica Gel 60 F-254) were a gift from E. Merck.

Animal experiments. Sprague-Dawley CD-COBS male rats (Charles River Breeding Laboratories Inc., Wilmington, MA), weighing 185$200 \mathrm{~g}$ at the start of the experiment, were used. Nephrotic syndrome was induced by a single intravenous injection of adriamycin $(7.5 \mathrm{mg} /$ $\mathrm{Kg}$ ), which corresponded to $105 \mathrm{mg} /$ square meter through the tail vein of nonanesthetized animals according to a method previously described (9). Controls rats received the solvent alone. The $T x$ synthetase inhibitor, UK- 38,485 , was injected $(20 \mathrm{mg} / \mathrm{kg})$ intraperitoneally t.i.d. for five consecutive days. $4 \mathrm{~h}$ after the last injection the kidneys were removed. Selected studies were performed in animals with the left kidney clamped for $5 \mathrm{~min}$ just before intravenous adriamycin. Furosemide $(12.5 \mathrm{mg} / \mathrm{Kg})$ was administered subcutaneously twice a day for $10 \mathrm{~d}$. Sulindac $(60 \mathrm{mg} / \mathrm{kg})$ was given as a single oral dose daily for three consecutive days.

For the determination of inulin clearance animals were anesthetized by intraperitoneal injection of Inactin $(16 \mathrm{mg} / 100 \mathrm{~g}$ of body weight), placed on a constant temperature table, and tracheotomized. $2 \mathrm{ml}$ of inulin (5\% in isotonic saline solution) was injected as priming dose, followed by constant infusion at $2.7 \mathrm{ml} / \mathrm{h}$. A 60 -min period of constant infusion was allowed before initiation of clearances. Urine was collected via a polyethylene tube inserted in the bladder. $0.1-\mathrm{ml}$ blood samples were obtained from a polyethylene tube (PE-50) inserted in the femoral artery. Plasma and urine inulin were determined using colorimetric assay adapted for microliter samples.

Glomerular isolation. Treated and control rats were anesthetized with ether and a cannula was inserted into the lower aorta. Subsequently, the aorta was clamped above the renal arteries, the renal veins were cut, and the kidneys were perfused with $60-80 \mathrm{ml}$ of Krebs-Ringer phosphate buffer (KRB) with the following composition: $120.29 \mathrm{mM}$ $\mathrm{NaCl}, 4.82 \mathrm{mM} \mathrm{KCl}, 1.21 \mathrm{mM} \mathrm{MgSO}_{4}, 2.57 \mathrm{mM} \mathrm{CaCl}_{2}$, and 15.6 $\mathrm{mM}$ phosphate buffer (pH 7.4). When kidney surfaces were completely blanched, the kidneys were removed and immediately immersed in ice-cold KRB. All subsequent preparative steps were performed at $4^{\circ} \mathrm{C}$. The renal capsules were removed and the cortex was separated from the medulla. The cortical segments were finely minced into 1-2$\mathrm{mm}$ fragments and the glomeruli were separated from residual cortical tissue by passing the homogenate through different size sieves and pressing the preparation through a $106 \mu \mathrm{m}$ sieve to exclude the tubules, and a $75-\mu \mathrm{m}$ sieve to retain the glomeruli. The sieved tissue, suspended in $\mathrm{KRB}, \mathrm{pH} 7.4$, was passed through a 25-gauge needle and centrifuged at $140 \mathrm{~g}$ for $120 \mathrm{~s}$. The supernatant was discarded, the pellet resuspended in the same buffer solution, passed again through the needle, and centrifuged. The purity of isolated glomeruli was determined microscopically by counting the number of glomerular and nonglomerular particles suspended in a given volume. The final pellet consisted of decapsulated glomeruli with $<2 \%$ tubular contamination. Electron microscopy of the normal isolated glomeruli showed well-preserved ultrastructure with intact endothelial lining, basement membranes, and distinct epithelial foot processes. The glomeruli of treated and control rats were always prepared in parallel.

Incubations. Freshly prepared glomeruli from control and treated rats were resuspended in $1 \mathrm{ml}$ of $\mathrm{KRB}$ at $37^{\circ} \mathrm{C}$ in room atmosphere in a Dubnoff shaking water bath (120 cycles/min). Incubation was usually stopped after $60 \mathrm{~min}$ by centrifugation at $3,000 \mathrm{~g}$ for $5 \mathrm{~min}$ and the supernatant of each tube was collected and frozen until PG radioimmunoassay. In selected experiments, the isolated glomeruli were incubated in presence of $\mathrm{AA}, 10$ and $20 \mu \mathrm{M}$, final concentration. Protein concentration was determined according to the method of Lowry et al. (10) with BSA as a standard. The concentration of glomerular proteins varied in different experiments $(200-500 \mu \mathrm{g} / \mathrm{ml})$ but was kept constant within the same experiment. For in vitro experiments, isolated glomeruli from normal rats were incubated with adriamycin $200 \mu \mathrm{g} / \mathrm{ml}$ and $1 \mathrm{mg} / \mathrm{ml}$ for 5 and $30 \mathrm{~min}$.

Sample preparation. Serum for studying platelet TxB2 production in response to endogenous thrombin was obtained by leaving multiple $1-\mathrm{ml}$ aliquots of native blood, collected by intracardiac puncture from ether-anesthetized animals, at $37^{\circ} \mathrm{C}$ for $30 \mathrm{~min}$, after the method previously reported (11). The prepared sera were frozen and kept at $-20^{\circ} \mathrm{C}$ until assayed.

Urines were collected using metabolic cages over a 24-h period, and their protein content was determined by the sulfosalicylic acid method. Serum and urine creatinine were determined by the method of Hare (12) using a Beckman analyzer (Astra 4 model, Beckman Instruments Inc., Fullerton, California). Creatinine and inulin clearances were calculated in the usual manner. Urinary TxB2, 6-Keto-PGF $1 \alpha$, and $\mathrm{PGE}_{2}$, which, within limits, reflect the renal synthesis of $\mathrm{TxA2}$, $P I_{2}$, and $P G E_{2}$, respectively, $(13,14)$ were measured by radioimmunoassay after extraction.

Renal tissue specimens were obtained from kidney biopsies. For light microscopy, fragments of the cortex were fixed in Dubosq-Brazil fluid $(80 \%$ alcohol, $150 \mathrm{ml}$; formol, $60 \mathrm{ml}$; acetic acid, $15 \mathrm{ml}$; picric acid, $1 \mathrm{~g}$ ) and embedded in paraffin. Sections of $2 \mu \mathrm{m}$ were stained with Masson's trichrome, hematoxylin and eosin, periodic acid staining (periodic acid-Schiff), and Wilder's reticulin. For electron microscopy, small pieces of the cortex were fixed with phosphate-buffered $2.5 \%$ glutaraldehyde (pH 7.2) for $6 \mathrm{~h}$, then rinsed in $0.2 \mathrm{M}$ cacodylate buffer (pH 7.4). Subsequently the samples were postfixed in $1 \%$ osmium tetroxide at $4^{\circ} \mathrm{C}$ for $1 \mathrm{~h}$, washed in buffer, and immersed in $0.5 \%$ Veronal uranyl acetate. Samples were then dehydrated through graded alcohol and embedded in Spurr resin. Ultrathin sections (60-80 nm) were cut on a Reichert Om $\mu$-2 ultramicrotome and examined with a Zeiss EM 109.

Assays. Radioimmunoassay: unextracted supernatants of glomerular preparations and extracted urinary samples were assayed for TxB2, 6Keto-PGF ${ }_{1 \alpha}$, the stable breakdown product of $\mathrm{PGI}_{2}$, and $\mathrm{PGE}_{2}$. Glomerular supernatants were diluted in $50 \mathrm{mM}$ phosphate buffer $(\mathrm{pH}$ 7.4) and assayed in a volume of $1.5 \mathrm{ml}$, at a final dilution of 1:121:30 for TxB2, 1:30 for 6-Keto-PGF $1 \alpha$, and 1:30 for PGE PG $_{2}$ Pere measured in extracted urinary samples diluted 1:30-1:120. 5,000 dpm of ${ }^{3} \mathrm{H}-\mathrm{TxB} 2$ or ${ }^{3} \mathrm{H}-6-\mathrm{Keto} \mathrm{PGF}_{1 \alpha}$ or ${ }^{3} \mathrm{H}-\mathrm{PGE}_{2}$ and appropriately diluted anti-TxB2 (final dilution 1:1,000,000) or anti-6-Keto-PGF la $_{\text {(final }}$ dilution 1:350,000) or anti- $\mathrm{PGE}_{2}$ sera (final dilution 1:50,000) were mixed and added in a volume of $1.25 \mathrm{ml}$ to each assay tube. The smallest concentrations that could be measured with $95 \%$ confidence were $50 \mathrm{pg} / \mathrm{ml}$ for TxB2, $100 \mathrm{pg} / \mathrm{ml}$ for $6-\mathrm{Keto}-\mathrm{PGF}_{\mathrm{l \alpha}}$, and $12.5 \mathrm{pg} /$ $\mathrm{ml}$ for $\mathrm{PGE}_{2}$. The detection limits were $0.6 \mathrm{ng}$ for $\mathrm{TxB2}, 3 \mathrm{ng}$ for 6Keto-PGF $1 a$, and $375 \mathrm{pg}$ for $\mathrm{PGE}_{2}$ per milliliter of glomerular supernatant, and $3 \mathrm{ng}$ for TxB2 and 6-Keto-PGF ${ }_{1 \alpha}$ and $375 \mathrm{pg}$ for $\mathrm{PGE}_{2}$ per milliliter of extracted urinary sample. Radioactivity of samples was counted in a liquid scintillation counter (Berthold model Betaszint b F 5000/300). Results were expressed as nanograms of TxB2, 6-Keto- 
$\mathrm{PGF}_{1 \alpha}$, and $\mathrm{PGE}_{2}$ per milligram of protein per hour for glomerular preparations and nanograms per day for urine.

TLC: isolated glomeruli $(\sim 1 \mathrm{mg}$ protein content per tube of glomerular incubation) were incubated in $\mathrm{KRB}$ containing $0.8 \mu \mathrm{Ci}$ ${ }^{14} \mathrm{C}$-AA in a final volume of $2 \mathrm{ml}$. The tubes were placed in a shaking water bath $(100 \mathrm{cycles} / \mathrm{min})$ at $37^{\circ} \mathrm{C}$ for $1 \mathrm{~h}$. Incubation was terminated by centrifugation at $4^{\circ} \mathrm{C}$ for $5 \mathrm{~min}$ at $3,000 \mathrm{~g}$ and the supernatant was removed. The pellet was washed thrice with $\mathrm{KRB}$ containing $1 \mathrm{mg} / \mathrm{ml}$ of essentially fatty acid-free albumin. PG synthesis was examined by incubating the washed, prelabeled glomeruli resuspended in $2 \mathrm{ml}$ of $\mathrm{KRB}$ containing $4 \mathrm{mM} \mathrm{CaCl}{ }_{2}$ at $37^{\circ} \mathrm{C}$ for $15 \mathrm{~min}$. Incubation was terminated by centrifugation as above. The supernatant was removed, immediately acidified to $\mathrm{pH} 3.0-3.5$ with $1 \mathrm{~N} \mathrm{HCl}$, and extracted twice with 3 vol of ethyl acetate. Recovery of ${ }^{14} \mathrm{C}-\mathrm{AA}$ was $90-95 \%$. The extracts were evaporated to dryness under nitrogen, resuspended in chloroform-ethanol (2:1), spotted on silica gel TLC plates together with 2-5 $\mu \mathrm{g}$ of PG and Tx standards, and developed twice in the organic phase of ethyl acetate/iso-octane/acetic acid/water (11:5:2:10, $\mathrm{vol} / \mathrm{vol})$. The standards were visualized by exposing the thin-layer plates to iodine vapor. The plates were cut into 30 segments and the silica gel from each segment was transferred to a scintillation vial; radioactivity was determined by scintillation counting in $8 \mathrm{ml}$ of a counting mixture (Ready-Solv MP, Beckman Analytical S.R.L., Milan, Italy). Counting efficiency, determined with a radioactive external standard, was $40-50 \%$.

Urine extraction. Urinary TxB2, 6-Keto- $\mathrm{PGF}_{1 \alpha}$, and $\mathrm{PGE}_{2}$ were measured by radioimmunoassay after extraction and silicic acid column chromatography. 2,000 cpm of ${ }^{3} \mathrm{H}-\mathrm{PGE}_{2}$ (New England Nuclear, 165

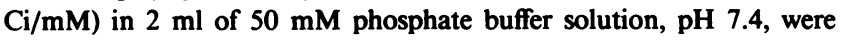
added to 6-ml aliquots of urine to serve as tracer during extraction and purification. Urine was acidified to $\mathrm{pH} 3.5$ with formic acid (99\%) and extracted with chloroform 1:3. The chloroform was removed by evaporation at $37^{\circ} \mathrm{C}$. $0.5 \mathrm{~g}$ of silicic acid was dissolved in $4 \mathrm{ml}$ of benzene/ethyl acetate (60:40) (solvent 1 ) and added to a small glass column $(6 \times 0.7 \mathrm{~cm})$. The column was washed with $5 \mathrm{ml}$ of benzene/ ethyl acetate/methanol (60:40:20) (solvent 2) and $1.5 \mathrm{ml}$ of solvent 1 . The extracted residue was dissolved in $0.2 \mathrm{ml}$ of benzene/ethyl acetate/ methanol (60:40:10) (solvent 3), and $0.8 \mathrm{ml}$ of solvent 1 was added. The mixture was applied to the column, and PG fractions were eluted with $5 \mathrm{ml}$ of solvent 1 (fraction I: PGA and PGB) and $5 \mathrm{ml}$ of solvent 2 (fraction II: PGE and PGF). Fraction II was taken to dryness at $37^{\circ} \mathrm{C}$ and dissolved with $6 \mathrm{ml}$ of $50 \mathrm{mM}$ phosphate buffer solution, pH 7.4. A portion of fraction II was radioimmunoassayed for TxB2, 6-Keto-PGF $F_{1 \alpha}$, and $\mathrm{PGE}_{2}$. Percentage recovery was calculated using $2,000 \mathrm{cpm}$ of ${ }^{3} \mathrm{H}-\mathrm{PGE}_{2}$. $\mathrm{PGE}_{2}$ was chosen as it was extracted with the same efficiency and eluted from the silicic acid column in the same fraction as TxB2 and 6-Keto-PGF ${ }_{1 \alpha}$. Overall recovery for all the compounds ranged from 60 to $75 \%$.

Statistical analysis. Results were analyzed by analysis of variance, unpaired $t$, and Duncan's multiple range tests. Results are expressed as mean $\pm 1 \mathrm{SD}$.

\section{Results}

Time-course of proteinuria and ultrastructural findings in adriamycin nephrosis. After a single intravenous injection of adriamycin $(7.5 \mathrm{mg} / \mathrm{kg})$, all treated animals developed a nephrotic syndrome. Proteinuria started 5-7 d after adriamycin, reached high values after $14 \mathrm{~d}(887 \pm 144 \mathrm{mg} / \mathrm{d})$, and persisted during the following weeks. Light microscopy showed only moderate swelling of glomerular visceral cells and some hyaline casts in the lumens of distal tubules, but under electron microscopy glomerular visceral epithelial cells displayed very pronounced changes, which consisted of extensive 'fusion' of foot processes replaced by expanses of epithelial cytoplasm, and many protein droplets were found within the cytoplasm.
No significant changes were found in the glomerular basement membrane, endothelium, or mesangium. Careful electron microscopy examination of a large number of glomeruli failed to reveal platelets or inflammatory cells.

$P G$ and Tx production by isolated glomeruli of rats with adriamycin nephrosis. Isolated glomeruli were studied from 21 rats given a single intravenous injection of adriamycin and 20 normal rats. Two groups of adriamycin-treated rats were considered. The first group of animals were killed $3 \mathrm{~d}$ after adriamycin when no proteinuria could be detected. The pattern of Tx and PG production from isolated glomeruli of these animals, measured by a radioimmunoassay, was comparable to controls. In contrast, isolated glomeruli from rats treated with adriamycin 14 and $30 \mathrm{~d}$ before, and proteinuric at the moment of the study, synthesized Tx at 4-5 times the rates of control glomeruli (Fig. 1). Synthesis of 6-Keto-PGF ${ }_{1 \alpha}$ and $\mathrm{PGE}_{2}$ increased transiently. However, $14 \mathrm{~d}$ after the single intravenous injection of adriamycin, $T x$ was the only AA metabolite that was persistently synthesized at increased rates, contrary to 6-Keto-PGF ${ }_{1 \alpha}$ and PGE $_{2}$ (Table I). Radio TLC confirmed the consistent increase in $\mathrm{Tx}$ synthesis by isolated glomeruli of adriamycin-treated animals in comparison with

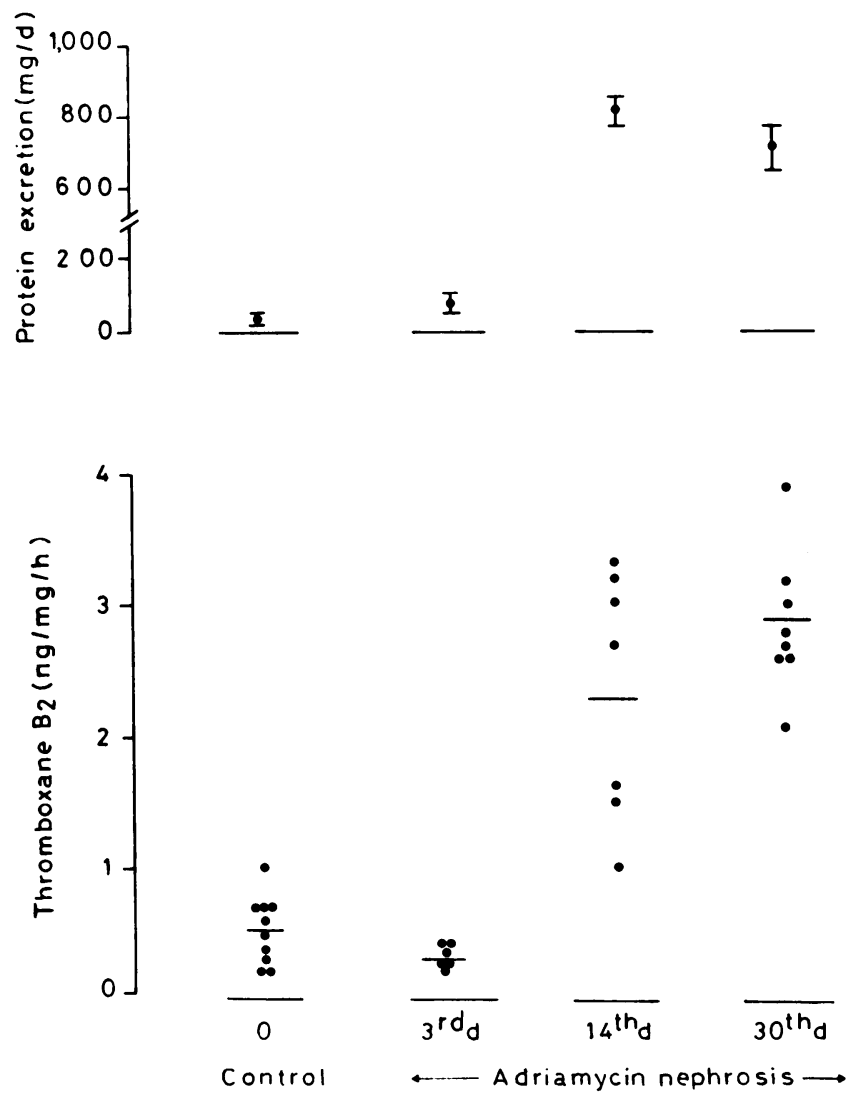

Figure 1. Protein excretion and isolated glomeruli Tx synthesis in rats at various intervals after a single intravenous adriamycin injection. TxB2 synthesis $(\mathrm{ng} / \mathrm{mg}$ protein/h, $n=10)$ was respectively $2.32 \pm 0.94$ and $2.86 \pm 0.53$ at 14 and $30 \mathrm{~d}$ when the animals were heavily proteinuric. Both values were significantly $(P<0.01)$ different from those in control animals $(0.51 \pm 0.26)$ and in animals treated with adriamycin $3 \mathrm{~d}$ before $(0.30 \pm 0.08)$ when proteinuria was within the normal range. 
Table I. Glomerular Synthesis and Urinary Excretion of $P G$ by Nephrotic Animals*

\begin{tabular}{llllll}
\hline & \multicolumn{2}{l}{$\begin{array}{l}\text { Isolated glomeruli } \\
(n g / m g \text { protein/h) }\end{array}$} & & $\begin{array}{l}\text { Urine } \\
(\text { ng/day })\end{array}$ & \\
\cline { 2 - 3 } \cline { 5 - 6 } & Controls & $\begin{array}{l}\text { Adriamycin } \\
\text { nephrosis }\end{array}$ & & Controls & $\begin{array}{l}\text { Adriamycin } \\
\text { nephrosis }\end{array}$ \\
\hline 6-keto-PGF & $1.95 \pm 0.50$ & $2.22 \pm 0.50$ & & $53.66 \pm 18.85$ & $65.55 \pm 25.02$ \\
PGE $_{2}$ & $3.48 \pm 0.40$ & $3.24 \pm 0.50$ & & $57.87 \pm 16.99$ & $69.48 \pm 29.32$
\end{tabular}

Unpaired $t$ test showed no significant difference for each comparison between the two groups.

* $14 \mathrm{~d}$ after a single intravenous injection of adriamycin.

controls. Synthesis of TxB2 accounted for $9.4 \%$ of the total recovered radioactivity in adriamycin-treated rats as against $4.7 \%$ in control rats. Synthesis of $\mathrm{PGF}_{2 \alpha}, 5.7 \%, \mathrm{PGE}_{2}, 5.2 \%$, 6-Keto- $\mathrm{PGF}_{1 \alpha}, 4.2 \%$, and $\mathrm{PGD}_{2}, 2.8 \%$ in adriamycin-treated animals were all similar to controls (respectively, 6.2, 4.8, 3.9, and $3.3 \%$ ). $45.8 \%$ of the total radioactivity in adriamycintreated animals and $49 \%$ in control animals was recovered unchanged as $\mathrm{C} 20: 4$. Total radioactivity recovered from the TLC plate was 5,000 dpm. Two other experiments gave similar results.

Urinary excretion of $T x$ in adriamycin nephrosis. In order to establish whether the increased glomerular Tx synthesis in nephrotic animals reflects a modification operating in vivo or is influenced by the in vitro manipulation of the kidneys, urinary excretion of $\mathrm{Tx}$ was measured in controls and nephrotic animals. Urinary excretion of TxB2 was significantly increased in experimental nephrosis, which was in parallel with the data from isolated glomeruli (Fig. 2). These findings are consistent with recent evidence that urinary excretion of $\mathrm{Tx}$ mostly reflects renal synthesis of the vasoactive parent compound in health and disease (15). Urinary excretion of 6-Keto-PGF ${ }_{1 \alpha}$ and $\mathrm{PGE}_{2}$ was not significantly modified in nephrotic animals (Table I).

Effect of a selective Tx synthetase inhibitor on glomerular $T x$ synthesis and proteinuria. In order to understand better the relationship between the increased Tx synthesis and proteinuria we studied two additional groups of animals injected with adriamycin $(7.5 \mathrm{mg} / \mathrm{kg})$; eight rats received three daily intraperitoneal injections of the Tx inhibitor, UK-38,485 (16), at doses of $20 \mathrm{mg} / \mathrm{kg}$ during the period of heavy proteinuria (days 14-18 after adriamycin), and eight rats received buffer alone for the same period. The dose of UK-38,485 used, when given to normal rats, caused $98 \%$ (from $142.8 \pm 76.7$ to $2.45 \pm 1.27 \mathrm{ng} / \mathrm{ml}$ ) inhibition of platelet $\mathrm{Tx}$ generation, as measured by the amount of Tx detected in serum after blood coagulation in vitro (11). All rats were killed on day $18,4 \mathrm{~h}$ after the last UK-38,485 or buffer injection.

As shown in Fig. 3, proteinuria during the treatment with UK-38,485 was significantly lower than both pretreatment values and the values in a comparable group of rats, not given the inhibitor, at the same interval from adriamycin injection. Urinary excretion of TxB2 was also significantly reduced during UK-38,485 treatment (Fig. 3). Sham-treated nephrotic controls presented no significant differences in urinary excretion of TxB2 before and after the period of buffer injection (18.34 \pm 6.52 vs. $23.72 \pm 8.24 \mathrm{ng} / \mathrm{d})$. We also found that $\mathrm{Tx}$ synthesis from isolated nephrotic glomeruli became normal

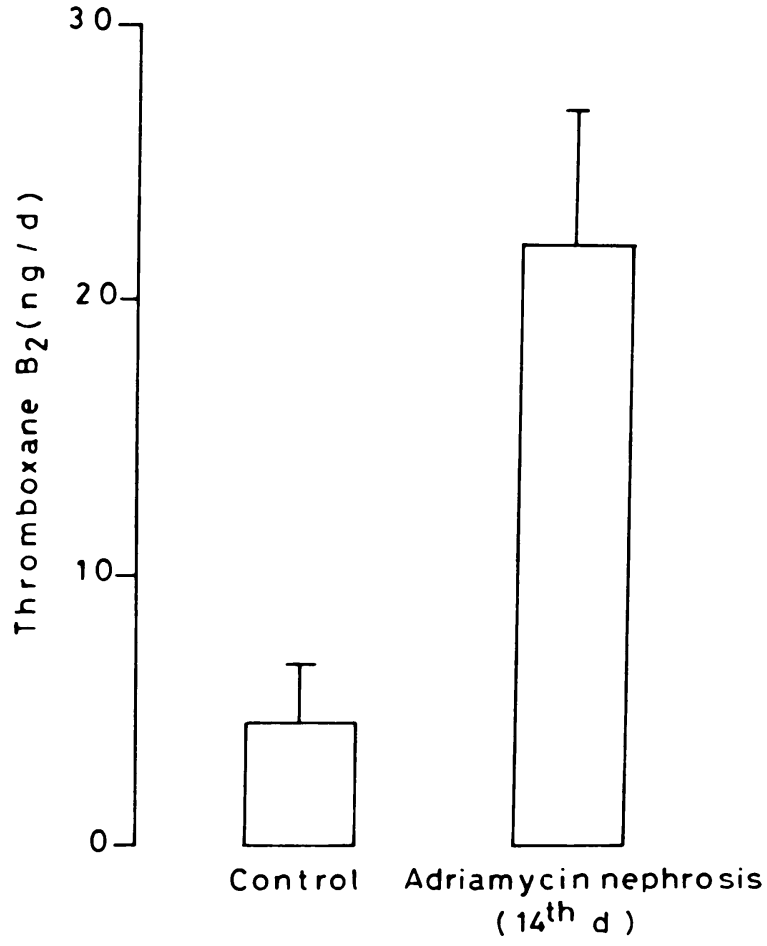

Figure 2. Urinary excretion of immunoreactive TxB2 in control and adriamycin treated rats. TxB2 excretion $(\mathrm{ng} / \mathrm{d}, n=8)$ was $4.50 \pm 1.2$ in control vs. $21.96 \pm 5.10$ in adriamycin $(7.5 \mathrm{mg} / \mathrm{kg})$ treated animals $14 \mathrm{~d}$ after the single intravenous injection $(P<0.001)$.

after the treatment with UK-38,485 (Fig. 3). On the contrary, 6-Keto-PGF $F_{1 \alpha}$ and $\mathrm{PGE}_{2}$ syntheses in nephrotic animals were not significantly modified by the treatment with UK-38,485 in isolated glomeruli $(2.26 \pm 0.76$ vs. $1.81 \pm 1.07 \mathrm{ng}$ of 6 -Keto$\mathrm{PGF}_{1 \alpha} / \mathrm{mg}$ protein per $\mathrm{h}$ and $3.61 \pm 0.93$ vs. $4.00 \pm 1.18 \mathrm{ng}$ of $\mathrm{PGE}_{2} / \mathrm{mg}$ protein per $\left.\mathrm{h}\right)$ as well as in urine $(58.14 \pm 21.98 \mathrm{vs}$. $56.71 \pm 23.10 \mathrm{ng}$ of $6-\mathrm{Keto}_{-\mathrm{PGF}} / \mathrm{d}$ and $68.14 \pm 20.01 \mathrm{vs}$. $73.43 \pm 25.85 \mathrm{ng}$ of $\mathrm{PGE}_{2} / \mathrm{d}$ ). Moreover, the treatment with UK-38,485 inhibited glomerular Tx synthesis in control rats $(3.00 \pm 0.50$ vs. $0.45 \pm 0.03 \mathrm{ng} / \mathrm{mg}$ protein per $\mathrm{h}$ ).

Effect of the selective $T x$ inhibitor $U K-38,485$ on renal function in normal and nephrotic animals. During treatment with UK-38,485 at a dose inhibiting serum Tx formation by $98 \%$, no significant changes in renal function, measured by endogenous creatinine and inulin clearances, could be detected in normal or nephrotic animals (creatinine clearances: $1.63 \pm 0.68$ vs. $1.30 \pm 0.19$ in normals and $1.36 \pm 0.35$ vs. $1.07 \pm 0.11 \mathrm{ml} / \mathrm{min}$ in nephrotics, inulin clearance rate: $1.20 \pm 0.12$ vs. $1.14 \pm 0.32$ in normals and $1.25 \pm 0.25$ vs. $1.18 \pm 0.28 \mathrm{ml} / \mathrm{min}$ per $100 \mathrm{~g}$ weight in nephrotics). These results are consistent with the findings of Lianos et al. (7), who showed in a model of nephrotoxic nephritis that inulin and para-aminohippurate clearances and filtration fraction were not worsened by UK-38,485.

Effects of sulindac on platelet and renal $T x$ generation. Sulindac $(60 \mathrm{mg} / \mathrm{kg})$ was given to 10 nephrotic animals from day 14 to day 16 after a single intravenous injection of adriamycin, and serum TxB2 concentration and urinary excretion of TxB2 were measured before and $2 \mathrm{~h}$ after the last dose. Sulindac inhibited serum TxB2 formation by $>70 \%$ in 

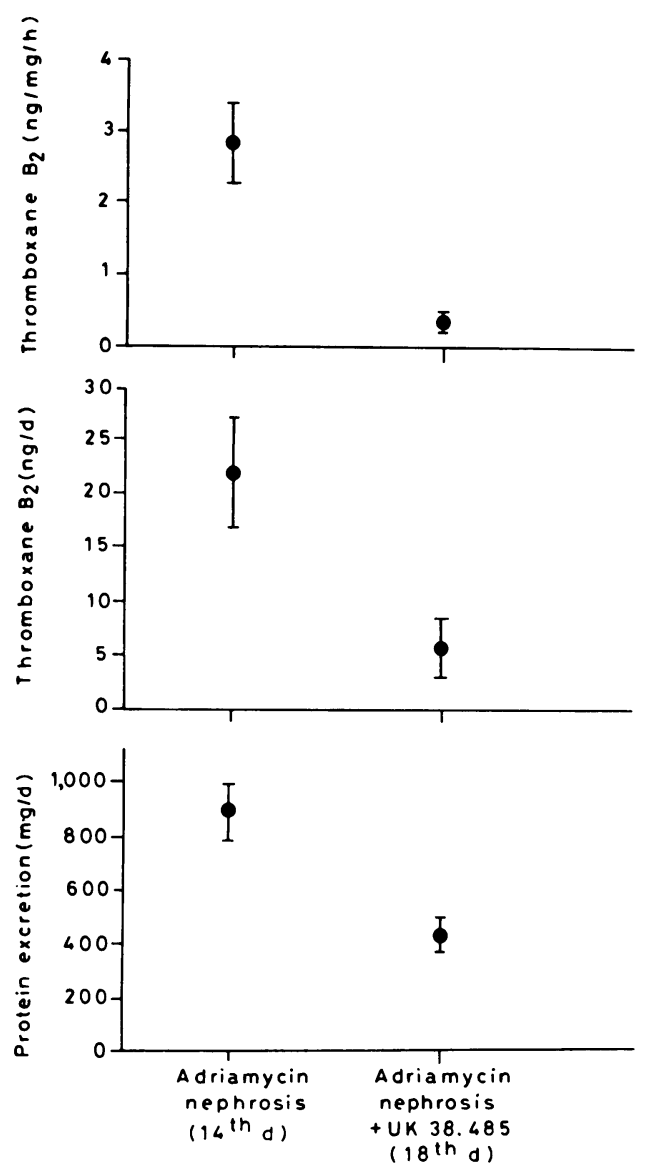

Figure 3. The effect of a selective Tx synthetase inhibitor (UK38,485 ) on isolated glomeruli Tx synthesis (top) and urinary excretion (middle) of TxB2. Rats $(n=8)$ were treated with the Tx inhibitor for $5 \mathrm{~d}$ when they were heavily proteinuric, as described in Methods. $4 \mathrm{~h}$ after the last UK-38,485 dose, glomerular TxB2 synthetic rates after death were significantly $(P<0.001)$ reduced $(0.41 \pm 0.64)$ compared with pretreatment values $(2.86 \pm 0.53 \mathrm{ng} / \mathrm{mg}$ protein per $h$ ). Before death, 24-h urinary excretion of TxB2 was also significantly $(P<0.001)$ reduced $(6.09 \pm 3.06)$ during UK-38,485 treatment, compared with pretreatment values $(21.96 \pm 5.10 \mathrm{ng} / \mathrm{d})$. The 24-h urinary protein excretion (bottom) were significantly $(P$ $<0.05)$ lower $(4.50 \pm 65)$ during the UK-38,485 treatment than before treatment $(887 \pm 144 \mathrm{mg} / \mathrm{d})$.

all animals, but had no effect on urinary excretion of TxB2 $(22.72 \pm 6.66$ vs. baseline $24.47 \pm 7.25 \mathrm{ng} / \mathrm{d})$. Urinary protein excretion as well was not significantly modified by sulindac in respect to the pretreatment values $(1,002 \pm 120$ vs. 1,050 $\pm 90 \mathrm{mg} / \mathrm{d})$.

Effect of $A A$ added in vitro on $P G$ and Tx synthesis by isolated glomeruli. In order to establish whether the increased Tx synthesis of isolated glomeruli in nephrotic animals was due to increased substrate availability, $T x$ production from isolated glomeruli was studied in vitro with and without the addition of 10 and $20 \mu \mathrm{M}$ exogenous AA. In the presence of AA, TxB2 and 6-Keto-PGF Ia syntheses from normal and nephrotic glomeruli (10 animals for each group) was not significantly modified compared to basal conditions (for TxB2: controls $=0.53 \pm 0.32$ and $0.48 \pm 0.18$ vs. $0.42 \pm 0.15$; nephrotics $=2.36 \pm 1.24$ and $2.51 \pm 1.65$ vs. $2.1 \pm 0.95 \mathrm{ng} / \mathrm{mg}$ protein per $\mathrm{h}$; for 6-Keto-PGF ${ }_{1 \alpha}$ : controls $=2.51 \pm 0.61$ and $2.66 \pm 0.59$ vs. $2.33 \pm 0.53$; nephrotics $=2.64 \pm 0.65$ and $2.75 \pm 0.67$ vs. $2.43 \pm 0.55 \mathrm{ng} / \mathrm{mg}$ protein per $\mathrm{h}$ ). At variance, $\mathrm{PGE}_{2}$ production of control and nephrotic isolated glomeruli in the presence of 10 and $20 \mu \mathrm{M}$ AA was higher, although not significantly different, from the values of unstimulated glomeruli (controls $=4.19 \pm 1.02$ and $4.47 \pm 1.15$ vs. $3.89 \pm 0.83$; nephrotics $=4.00 \pm 1.13$ and $4.45 \pm 1.05$ vs. $3.63 \pm 0.68 \mathrm{ng} / \mathrm{mg}$ protein per h).

Effect of chronic furosemide on Tx synthesis by isolated glomeruli. 20 normal rats were injected with furosemide or buffer for $10 \mathrm{~d}$ in order to achieve maximum stimulation of the renin-angiotensin axis. Although this was an acute experiment and may not be fully representative, we decided to kill the animals at $14 \mathrm{~d}$, when proteinuria usually reached top values. TxB2 synthesis by glomeruli isolated from furosemidetreated animals was significantly elevated $(0.91 \pm 0.08$ vs. $0.59 \pm 0.10, \mathrm{ng} / \mathrm{mg}$ protein per $\mathrm{h}$ in controls, $P<0.001)$. However, Tx generation by isolated glomeruli from these normal animals was still significantly $(P<0.001)$ lower than in the glomeruli of nephrotic rats studied simultaneously $(2.5 \pm 1.03$ $\mathrm{ng} / \mathrm{mg}$ protein per $\mathrm{h}$ ). These results suggest that adriamycin enhances glomerular Tx synthesis with a mechanism independent from stimulation of the renin-angiotensin system.

Effect of the nephrotic syndrome per se on glomerular $P G$ and $T x$ production. In order further to exclude that the increased glomerular $\mathrm{Tx}$ production in adriamycin nephrosis is simply a consequence of the nephrotic syndrome, we performed some additional experiments. 10 rats were given adriamycin in a single intravenous injection $(7.5 \mathrm{mg} / \mathrm{kg})$, but the left renal artery was clamped just before the injection. The clamp was removed 15 min later. 2 wk later all the animals were heavily proteinuric, but the left kidney was protected from adriamycin toxicity and on electron microscopy examination appeared normal, whereas adriamycin-induced changes were more severe than usual in the right kidney. Thus, it appears that direct exposure of kidney to adriamycin in vivo is necessary for the demonstration of glomerular damage. This model serves to study PG production by isolated glomeruli in normal or diseased kidneys in animals with heavy proteinuria and nephrotic syndrome. Failure to detect any abnormality in the generation of AA metabolites by the left kidney indicates that the nephrotic syndrome per se has no effect on glomerular synthesis of PG and Tx (Table II). Urinary excretion of TxB2 from animals affected by unilateral disease was slightly, but not significantly, decreased in comparison to values obtained in the conventional two kidneys model (16.8 \pm 3.62 vs. $22.31 \pm 4.51 \mathrm{ng} / \mathrm{d})$.

Acute in vitro and in vivo effect of adriamycin on glomerular

Table II. Synthesis of TxB2 by

Isolated Glomeruli*

\begin{tabular}{lll}
\hline & \multicolumn{2}{c}{ Adriamycin nephrosis } \\
\cline { 2 - 3 } & Left renal artery clamp & Controls \\
\hline Left kidney & $1.20 \pm 0.15$ & $0.95 \pm 0.21$ \\
Right kidney & $4.26 \pm 0.80$ & $0.50 \pm 0.10 \ddagger$
\end{tabular}

* Nanogram per milligram protein per hour. $\ddagger P<0.001$ (unpaired $t$ test). 
$P G$ and Tx synthesis. We investigated whether the altered AA metabolism was the immediate consequence of exposure of the glomerular structure to adriamycin by incubating the glomerular preparation with adriamycin $(200 \mu \mathrm{g} / \mathrm{ml}$ and 1 $\mathrm{mg} / \mathrm{ml}$ ) in vitro for 5 or $30 \mathrm{~min}$. This significantly depresses the isolated glomeruli's capacity to synthesize $\mathrm{Tx}$, compared to controls, i.e., $200 \mu \mathrm{g} / \mathrm{ml}$ adriamycin: $0.26 \pm 0.15$ vs. $0.81 \pm 0.11$ $\mathrm{ng} / \mathrm{mg}$ protein per $\mathrm{h}$ for $5 \mathrm{~min}$ incubation $(P<0.001)$, and $0.09 \pm 0.04$ vs. $0.75 \pm 0.06 \mathrm{ng} / \mathrm{mg}$ protein per $\mathrm{h}$ for $30 \mathrm{~min}$ incubation $(P<0.001) ; 1 \mathrm{mg} / \mathrm{ml}$ adriamycin: $0.23 \pm 0.10$ vs. $0.63 \pm 0.11 \mathrm{ng} / \mathrm{mg}$ protein per $\mathrm{h}$ for $5 \mathrm{~min}(P<0.001)$, and $0.12 \pm 0.04$ vs. $0.77 \pm 0.05 \mathrm{ng} / \mathrm{mg}$ protein per $\mathrm{h}$ for $30 \mathrm{~min}$ incubation $(P<0.001)$. Similarly, isolated glomeruli of rats injected with $7.5 \mathrm{mg} / \mathrm{kg}$ adriamycin and killed $5 \mathrm{~min}$ and 12 $h$ after the treatment generated significantly less arachidonate metabolites than controls $(0.11 \pm 0.05$ vs. $0.67 \pm 0.06 \quad(P$ $<0.001)$ and $0.14 \pm 0.07$ vs. $0.7 \pm 0.09(P<0.001) \mathrm{ng} / \mathrm{mg}$ protein per $h$, respectively). These experiments indicate that adriamycin is not directly responsible for the exaggerated glomerular synthesis of $\mathrm{Tx}$ observed in the experimental model described so far.

\section{Discussion}

The finding that several experimental models of glomerular damage show certain common quantitative and qualitative alterations in AA metabolism suggests the importance of this modulatory pathway in glomerular pathophysiology (17-19). Glomerular production of TxB2 might be one of the factors responsible for the altered glomerular filtration rate in disease (8).

Indeed, in experimental nephrotoxic nephritis, a marked initial increment of glomerular $\mathrm{Tx}$ has been demonstrated, which parallels the decrements in renal blood flow and glomerular filtration rate seen a few hours after the induction of the disease. In contrast, the glomerular synthesis of vasodilatory $\mathrm{PGE}_{2}$ increases progressively in the following days and appears to account for the spontaneous recovery in renal blood flow and glomerular filtration rate observed in these animals after $14 \mathrm{~d}(20)$. In this context, Lianos et al. (7) also found in a rat model of nephrotoxic nephritis that $T x$ was the only arachidonate metabolite that was persistently synthesized at an increased level during prolonged incubation of glomerular preparations. More important, they found a linear correlation between proteinuria and the increase in glomerular $\mathrm{Tx}$ synthesis. As the authors commented, this correlation could represent a cause-effect relationship, or both glomerular $\mathrm{Tx}$ and proteinuria could be independent markers of the extent of glomerular injury.

The results of the present study show that a model of glomerular injury quite different from those studied previously was also characterized by a selective increase in urinary excretion and glomerular production of TxB2. We also found transient differences between normal and nephrotic animals in other products of AA metabolism, but these differences never reached statistical significance. Together with previous observations in nephrotoxic nephritis and in a model of acute renal failure due to bilateral ureteral obstruction, these results might be taken to suggest that glomerular function in normal conditions might be critically under the control of Tx synthesis (21).
Our study also investigated the relationship between altered Tx synthesis and proteinuria. The adriamycin model of nephrotic syndrome in rats is particularly suitable, in that the time course and the amount of protein excretion are well defined (9). A single adriamycin injection in rats induces a nephrotic syndrome with proteinuria appearing $5 \mathrm{~d}$ after injection, and reaching high values after $14 \mathrm{~d}$. At variance with aminonucleoside nephrosis, where animals are free of proteinuria after $4 \mathbf{w k}$, in adriamycin nephrosis proteinuria persists several months (22). Under light microscopy, pathological changes are almost unremarkable, consisting in moderate swelling of glomerular visceral epithelial cells and in some tubular casts. In contrast, ultrastructural findings comprise marked changes of podocytes with extensive 'fusion' of foot processes and pronounced 'activation' of glomerular visceral epithelial cells.

Our results indicate that Tx synthesis by isolated glomeruli significantly increased in concomitance with the onset of proteinuria, and reached a plateau as constant values for protein excretion were attained. The significant reduction in proteinuria noted after administration of UK-38,485, a selective Tx synthetase inhibitor, indicates that in our model increased glomerular Tx synthesis might be one of the factors responsible for persistent proteinuria. An interesting feature of our study is also that the $\mathbf{T x}$ inhibitor, at a dose inhibiting platelet $\mathbf{T x}$ production by $98 \%$, normalized but did not abolish the exaggerated Tx production by nephrotic glomeruli. This has also been observed by Patrignani et al. (23) who reported failure of dazoxiben to reduce urinary $\mathrm{TxB} 2$ excretion by $>30 \%$ in man. As these authors speculated, this could be attributed to more than one factor, i.e., rapidly reversible inhibition and different sensitivity of cortex Tx-synthase compared to the platelet enzyme.

Appropriate measurements of creatinine and inulin clearances in normal and nephrotic animals exposed to UK-38,485 indicated that our results were not influenced by modifications of glomerular filtration rate induced by the drug. We also found that the increased $T x$ synthesis in nephrotic glomeruli was not the immediate result of glomerular capillaries being exposed to adriamycin, since isolated glomeruli exposed to the drug in vitro showed a marked reduction in their capacity to generate TxB2. Similar results were obtained when isolated glomeruli from rats killed $5 \mathrm{~min}$ and $12 \mathrm{~h}$ after adriamycin injection were examined. Thus, while the latter findings appear to reflect a nonspecific, direct, acute toxic effect of adriamycin on glomerular capillaries, the marked increase in urinary excretion and glomerular production of TxB2 appears peculiar to the nephrotic syndrome.

As for the mechanism underlying the alteration of glomerular AA metabolism in experimental nephrosis, an increase in precursor availability might be a conceivable explanation of the enhanced glomerular TxB2 synthesis. However, failure to neutralize the difference between normal and nephrotic rats in the presence of an excess of AA added in vitro makes such an event unlikely. An alternative possibility is that the altered glomerular AA metabolism reflects activation of the reninangiotensin system which characterizes the nephrotic condition (24). If this is the case, captopril, an inhibitor of angiotensin I-converting enzyme, should eliminate the exaggerated $T x$ output from nephrotic glomeruli. However, it has recently been proven that captopril, besides inhibiting the renin-angio- 
tensin axis, also directly stimulates the renal AA metabolism (25). To overcome this problem we studied a group of normal rats under chronic furosemide treatment, which had limited access to water, to ensure maximal stimulation of the reninangiotensin system (26). The glomerular $T x$ synthesis was significantly higher in adriamycin than in furosemide-treated animals, so it is unlikely that the altered AA metabolism observed in nephrotic syndrome is simply a consequence of stimulation of the renin-angiotensin system.

Finally, the increased production of $\mathrm{Tx}$ by isolated glomeruli in adriamycin nephrosis might be a consequence of the hypoalbuminemia which develops with the nephrotic syndrome. The rationale for this possibility derives from studies by Yoshida and Aoki (27) and by Schieppati et al. (28), who demonstrated that hypoalbuminemia of the nephrotic syndrome raises the capacity of circulating platelets to form $\mathrm{Tx}$. However, the present study shows that blood modifications induced by the nephrotic syndrome do not alter the AA metabolism, in that isolated glomeruli from kidneys unilaterally protected from adriamycin toxicity, but taken from animals with heavy proteinuria, generated a normal amount of TxB2.

As regards the cellular origin of $\mathrm{TxB2}$, it is reasonable to believe that glomerular epithelial cells are the major source of $T x$ in our experimental condition. In our model, at variance with previous ones, no monocyte or leukocyte infiltration and no platelet deposition could be detected, and the only ultrastructural abnormalities were confined to visceral epithelial cells (9). Since morphological evidence does not necessarily rule out the possibility of contamination of our glomerular preparation with entrapped platelets and leukoytes, we studied the effect of sulindac in adriamycin nephrosis. To clarify better the issue of the urinary TxB2 origin we used the pharmacological approach proposed by Ciabattoni et al. (29). These authors provided evidence in humans that sulindac substantially inhibits Tx synthesis by circulating cells but does not affect renal Tx synthesis as measured by urinary excretion of TxB2. These studies give useful information on the origin of urinary TxB2, distinguishing between circulating cells and intrarenal Tx synthesis.

We repeated the same experiments in nephrotic rats. Despite the fact that platelet count in these animals rises to twice basal values $14 \mathrm{~d}$ after the treatment with adriamycin (30), we found that the dose of sulindac used inhibited platelet TxB2 by $>70 \%$ in all animals but did not affect urinary excretion of TxB2. This would suggest that the increased urinary excretion of $T x$ in experimental nephrosis is unlikely to be of platelet origin, but possibly reflects an increased intrarenal synthesis. Increased Tx production can alter glomerular function in a complex way. It was suggested that basal renal vascular tone is in some way under the influence of TxA2, since imidazole (31) increases renal blood flow in animals by reducing renal resistance. Moreover, evidence is accumulating that this potent vasoactive substance may contribute to the intense afferent arteriolar vasoconstriction that occurs with ureteral obstruction. The results of the present study suggest that TxA2 could have an additional effect on glomerular function by altering the basement membrane's permeability to proteins. In this context, a possible role of PG in modulating selectivity and permeability of the glomerular barrier can be inferred from old studies in which indomethacin (32) was reported convincingly, though inconsistently (33), to reduce proteinuria in animals and humans. However, the conflicting data obtained with indomethacin might be interpreted as a consequence of nonselective inhibition of PG with different, and possibly opposite, activities in the glomeruli, thus making it difficult to assess the net result.

Appropriate studies are warranted to evaluate the potential role of drugs selectively inhibiting $T x$ synthesis in the treatment of proteinuria.

\section{Acknowledgments}

The authors are grateful to Drs. Manuela Livio and Ariela Benigni for fruitful cooperation, and to Professor Carlo Patrono for discussion and constructive criticism. Cristina Signorelli and Judith Baggott helped prepare the manuscript.

This study was supported by a grant from the National Research Council (CNR) (Program 'Tecniche Sostitutive di Funzioni d'Organo'; Progetto Finalizzato 'Medicina Preventiva' No. 82.01307.04).

\section{References}

1. Smith, W. L., and T. G. Bell. 1978. Immunohistochemical localization of the prostaglandin-forming cyclo-oxygenase in renal cortex. Am. J. Physiol. 235:451-457.

2. Hassid, A., M. Konieczkowsky, and M. J. Dunn. 1979. Prostaglandin synthesis in isolated rat kidney glomeruli. Proc. Natl. Acad. Sci. USA. 76:1155-1159.

3. Schlondorff, D., S. Roczniak, J. A. Satriano, and V. W. Folkert. 1980. Prostaglandin synthesis by isolated rat glomeruli: effect of angiotensin II. Am. J. Physiol. 238:486-495.

4. Folkert, V. W., and D. Schlondorff. 1979. Prostaglandin synthesis in isolated glomeruli. Prostaglandins. 17:79-86.

5. Sraer, J., N. Ardaillou, J. D. Sraer, and R. Ardaillou. 1982. In vitro prostaglandin synthesis by human glomeruli and papillae. Prostaglandins. 23:855-864.

6. Sraer, J. D., L. Moulonguet-Doleris, F. Delarue, J. Sraer, and R. Ardaillou. 1981. Prostaglandin synthesis by glomeruli isolated from rats with glycerol-induced acute renal failure. Circ. Res. 49:775-783.

7. Lianos, E. A., G. A. Andres, and M. J. Dunn. 1983. Glomerular prostaglandin and thromboxane synthesis in rat nephrotoxic serum nephritis. J. Clin. Invest. 72:1439-1448.

8. Dunn, M. J. 1983. The role of arachidonic acid metabolites in glomerulonephritis. In Glomerular Injury: 300 Years After Morgagni. T. Bertani and G. Remuzzi, editors. Wichtig Editore, Milan. 75-88.

9. Bertani, T., A. Poggi, R. Pozzoni, F. Delaini, G. Sacchi, Y. Thoua, G. Mecca, G. Remuzzi, and M. B. Donati. 1982. Adriamycininduced nephrotic syndrome in rats. Sequence of pathologic events. Lab. Invest. 46:16-23.

10. Lowry, O. H., N. J. Rosebrough, A. L. Farr, and R. J. Randall. 1951. Protein measurement with the folin phenol reagent. J. Biol. Chem. 193:265-275.

11. Remuzzi, G., A. Benigni, P. Dodesini, A. Schieppati, M. Livio, J. S. Day, W. L. Smith, E. Pinca, P. Patrignani, and C. Patrono. 1983. Reduced platelet thromboxane formation in uremia. Evidence for a functional cyclooxygenase defect. J. Clin. Invest. 71:762-768.

12. Hare, R. S. 1950. Endogenous creatinine in serum and urine. Proc. Soc. Exp. Biol. Med. 74:148-151.

13. Frölich, J. C., T. W. Wilson, B. J. Sweetman, M. Smigel, A. S. Nies, K. Carr, J. T. Watson, and J. A. Oates. 1975. Urinary prostaglandins. Identification and origin. J. Clin. Invest. 55:763-770.

14. Pugliese, F., and G. Ciabattoni. 1983. Investigation of renal arachidonic acid metabolites by radioimmunoassay. In Prostaglandins and the Kidney. M. J. Dunn, C. Patrono, and G. A. Cinotti, editors. Plenum Publishing Corp., New York. 83-98. 
15. Fitzgerald, G. A., A. K. Pedersen, and C. Patrono. 1983. Analysis of prostacyclin and thromboxane biosynthesis in cardiovascular disease. Circulation. 67:1174-77.

16. Parry, M. J., M. J. Randall, E. Hawkeswood, P. E. Cross, and R. P. Dickinson. 1982. Enhanced production of prostacyclin in blood after treatment with selective thromboxane synthetase inhibitor, UK38,485. Br. J. Pharmacol. 77:547. (Abstr.)

17. Zipser, R., S. Myers, and P. Needleman. 1980. Exaggerated prostaglandin and thromboxane synthesis in the rabbit with renal vein constriction. Circ. Res. 47:231-237.

18. Benabe, J. E., S. Klahr, M. K. Hoffman, and A. R. Morrison. 1980. Production of thromboxane A2 by the kidney in glycerolinduced acute renal failure in the rabbit. Prostaglandins. 19:333-347.

19. Dighe, K. K., G. W. Smith, A. Ungar, and P. H. Whelpdale. 1978. Renal prostaglandins in renal hypertensive dogs. Clin. Sci. Mol. Med. 54:561-566.

20. Stork, J. E., and M. J. Dunn. 1984. Immuneglomerulonephritis in the rat: renal function, thromboxane A2 (TxA2) and PGE2. Clin. Res. 32:565A.

21. Morrison, A. R., K. Nishikawa, and P. Needleman. 1978. Thromboxane A2 biosynthesis in the ureter obstructed isolated perfused kidney of the rabbit. J. Pharmacol. Exp. Ther. 205:1-8.

22. Bertani, T., and G. Remuzzi. 1983. Epithelial cell damage. In Glomerular Injury: 300 Years After Morgagni. T. Bertani and G. Remuzzi, editors. Wichtig Editore, Milan. 163-178.

23. Patrignani, P., P. Filabozzi, F. Catella, F. Pugliese, and C. Patrono. 1984. Differential effects of dazoxiben, a selective thromboxane-synthase inhibitor, on platelet and renal prostaglandin-endoperoxide metabolism. J. Pharmacol. Exp. Ther. 228:472-477.

24. Lifschitz, M. D., and J. H. Stein. 1982. Renal vasoactive hormones. In The Kidney. B. M. Brenner and F. C. Rector, editors. W. B. Saunders Co., Philadelphia, London, and Toronto. 650-720.
25. Swartz, S. L., G. H. Williams, N. K. Hollenberg, L. Levine, R. G. Dluhy, and T. J. Moore. 1980. Captopril-induced changes in prostaglandin production. Relationship to vascular responses in normal man. J. Clin. Invest. 65:1257-1264.

26. Weber, P. C., B. Scherer, and C. Larsson. 1977. Increase of free arachidonic acid by furosemide in man as the cause of prostaglandin and renin release. Eur. J. Pharmacol. 41:329-332.

27. Yoshida, N., and N. Aoki. 1978. Release of arachidonic acid from human platelets. A key role for the potentiation of platelet aggregability in normal subjects as well as in those with nephrotic syndrome. Blood. 52:969-977.

28. Schieppati, A., P. Dodesini, A. Benigni, M. Massazza, G. Mecca, G. Remuzzi, M. Livio, G. de Gaetano, and E. C. Rossi. 1984. The metabolism of arachidonic acid by platelets in nephrotic syndrome. Kidney Int. 25:671-676.

29. Ciabattoni, G., G. A. Cinotti, and C. Patrono. 1980. Renal effects of antiinflammatory drugs. Eur. J. Rheumatol. Inflammation. 3:210-221.

30. Poggi, A., L. Komblihtt, F. Delaini, T. Colombo, L. Mussoni, I. Reyers, and M. B. Donati. 1979. Delayed hypercoagulability after a single dose of Adriamycin to normal rats. Thromb Res. 16:639-650.

31. Brenner, B. M., and N. Schor. 1983. Studies of prostaglandin action on the glomerular microcirculation. In Prostaglandins and the Kidney. M. J. Dunn, C. Patrono, and G. A. Cinotti, editors. Plenum Publishing Corp., New York. 125-132.

32. Michielsen, P., R. Verberckmoes, V. Desmet, and W. Hermerijckx. 1969. Evolution histologique des glomérulonéphrites proliferatives diffuses traitées par l'indométhacine. J. Urol. Nephrol. 75:315-319.

33. Glassock, R. J., A. H. Cohen, C. M. Bennett, and M. MartinezMaldonado. 1982. Primary glomerular diseases. In The Kidney. B. M. Brenner and F. C. Rector, editors. W. B. Saunders Co., Philadelphia, London, and Toronto. 1351-1492. 